\title{
Exercise capacity and extent of resection as predictors of surgical risk in lung cancer
}

\author{
M.H. Brutsche*, A. Spiliopoulos**, C.T. Bolliger***, M. Licker**, J-G. Frey*, J-M. Tschopp*
}

Exercise capacity and extent of resection as predictors of surgical risk in lung cancer. M.H. Brutsche, A. Spiliopoulos, C.T. Bolliger, M. Licker, J-G. Frey, J-M. Tschopp. (C)ERS Journals Ltd 2000.

ABSTRACT: Lung resection remains the most effective treatment for non-small cell lung cancer (NSCLC). However, there is no consensus about reliable operative risk assessment in these patients. The aim of this study was to identify predictors of postoperative complications and death after lung resection for NSCLC.

In this prospective trial, 125 of $142(88 \%)$ consecutive NSCLC patients from 1990 to August 1997 had complete data sets. All underwent functional assessment including spirometry and cardiopulmonary exercise tests and lung resection via thoracotomy.

Complications occurred in 31 of $125(25 \%)$ patients including $2(1.6 \%)$ deaths. On logistic regression analysis, only maximal oxygen uptake $\left(V^{\prime} \mathrm{O}_{2}, \max \right) \cdot \mathrm{kg} \mathrm{body} \mathrm{weight}^{-1}$ expressed as a percentage of the predicted value $(\mathbf{p}<0.0001)$ and the estimated extent of lung tissue resection $(\mathrm{p}=\mathbf{0 . 0 2})$ were independent predictors of postoperative complications. Six of seven patients with a $V^{\prime} \mathrm{O}_{2}$, max $\cdot \mathrm{kg}_{\text {body }}$ weight $^{-1}$ of $<60 \%$ pred, but only eight of 65 with values $>90 \%$ pred, exhibited postoperative complications.

Maximal oxygen uptake and the estimated extent of lung tissue resection are independent predictors of postoperative complications. These simple parameters should be integrated into the preoperative decision analysis for operability in patients undergoing lung resection for lung cancer.

Eur Respir J 2000; 15: 828-832.

\begin{abstract}
*Centre Valaisan de Pneumologie, Montana, **Dept of Thoracic Surgery, University Hospital of Geneva, Geneva, ***Division of Pneumology, University Hospital of Basle, Basle, Switzerland.
\end{abstract}

Correspondence: J-M. Tschopp Centre Valaisan de Pneumologie CH-3962 Montana Switzerland

Fax: 41276038181

Keywords: Aerobic capacity cardiopulmonary exercise testing lung cancer non-small cell lung cancer operability thoracotomy

Received: March 311999

Accepted after revision February 122000
Lung cancer continues to have a dismal prognosis, with a 5 -yr survival rate of only $13.4 \%$ [1]. Lung resection remains the most effective treatment for non-small cell lung cancer (NSCLC) with a 5-yr survival rate after resection that ranges from 60 (stage IA) to $26 \%$ (stage IIIA) [2]. Nevertheless, resection rates are quite low and vary significantly between different countries. Cancer registrybased studies show resection rates of only $10-20 \%$ in Europe $[3,4]$. It is possible, that overly restrictive preoperative selection and preselection by nonspecialists, for example for patients $>70$ yrs of age, preclude a potentially curative therapy for some patients. Efforts must focus on establishing proper criteria for inoperability. To date, there is no consensus concerning reliable risk assessment in these patients. The decision to operate is usually based on standard spirometric criteria including radionuclide-calculated estimates of postoperative forced expiratory volume in one second (FEV1), known to be associated with postoperative morbidity and probably mortality [5].

Since 1982, cardiopulmonary exercise tests (CPETs) have been reported to be useful in the functional evaluation of lung resection candidates [6]. However, in different studies, different exercise parameters and different recommendations are given. EugENE et al. [6] underlined the importance of the absolute value of maximal oxygen uptake $\left(V^{\prime} \mathrm{O}_{2}, \max \right)$; SMITH et al. [7] and BECHARD and WeTSTEIN [8] found $V^{\prime} \mathrm{O}_{2}$, max $\cdot \mathrm{kg}$ body weight ${ }^{-1}$ to be the best parameter; Bolliger et al. [9, 10] underlined the importance of poor exercise performance and especially $V^{\prime} \mathrm{O}_{2}$,max $\cdot \mathrm{kg}$ body weight ${ }^{-1}$ expressed as a percentage of the predicted value as the best predictor of postoperative complications. In other studies [11-13], $V^{\prime} \mathrm{O}_{2}$, max was not a definite predictor of postoperative complications. In the existing literature, neither guidelines, nor precise cut-off values for CPET parameters are clearly established.

The aim of this study was to establish predictors of postoperative complications based on easily accessible lung functions and cardiorespiratory exercise testing in order to establish objective operability criteria in lung cancer patients scheduled for pulmonary resection.

\section{Material and methods}

\section{Study subjects and design}

The study was designed as a prospective study looking at the value of different preoperative variables in predicting postoperative complications including death.

All patients undergoing consecutive lung resections for lung cancer and attending the Centre Valaisan de Pneumologie (Montana, Switzerland), a non-university chest hospital were included in the study from 1990 to August 1997. The functional assessment was carried out after optimization of the patient's treatment and consisted of general parameters (age, sex, body mass index), disease parameters (oncological stage, histological type), pulmonary function 
tests (forced vital capacity (FVC), forced expiratory volume in one second (FEV1), FEV1/FVC) and symptom-limited CPET. Generally, the decision to operate was based on clinical grounds, taking into account clinical parameters and results of investigations such as laboratory findings, lung function tests and radiological staging including computed tomography. Patients with a FEV1 of $<35 \%$, a New York Heart Association dyspnoea grade of $\geq$ III, hypercapnia (arterial carbon dioxide tension $\left(P \mathrm{a}, \mathrm{CO}_{2}\right)$ $>6.0 \mathrm{kPa}(45 \mathrm{mmHg})$ breathing ambient air) or intractable cardiac failure were excluded from operation.

Demographic, spirometric and exercise test data, together with the oncological postoperative staging and histological types of lung cancer are shown in table 1 .

\section{Pulmonary function tests}

Spirometry before and after bronchodilator therapy was performed by two experienced technicians and according to American Thoracic Society criteria $[14,15]$ using a Sensormedics 9000 IV Spirometer (Sensormedics, Bilthoven, the Netherlands).

\section{Cardiopulmonary exercise tests}

All patients underwent symptom-limited CPETs on a cycle ergometer (Sensormedics 2200 SP; Sensormedics). After a 2-min warm-up period at $20 \mathrm{~W}$, a ramp protocol with $20-\mathrm{W} \cdot \mathrm{min}^{-1}$ workload increases was started. The exercise test was stopped when the patients were exhausted, or at any electrocardiographic signs or clinical symptoms of myocardial ischaemia, including a fall in systolic blood pressure.

As generally accepted and tested in a comparable population $[9,12,16]$, the equation proposed by Cherniak $[15$, 17], derived in nonsmoking Caucasians, was used to calcuculate the predicted normal values for FEV1. For $V^{\prime} \mathrm{O}_{2}$, max and $V^{\prime} \mathrm{O}_{2}$, max $\cdot \mathrm{kg}$ body weight ${ }^{-1}$ the equations of JONES and CAMPBELL [18] with correction for cycle ergometry were applied.

\section{Surgical procedures and postoperative care}

All patients underwent open thoracic surgery by the same team of specialized thoracic surgeons, anaesthetists and pulmonologists, who were involved in a programme of total quality management including a study on cost effectiveness (the results of which have been published elsewhere $[19,20])$. The patients were extubated within $0.5-4$ $\mathrm{h}$ after the intervention, mainly in the operating theatre at the end of the operation. Thereafter, they were transferred to a specialized intermediate care unit for $2-4$ days. No patient required transfer to the intensive care unit. Thromboembolic prophylaxis was administered in the form of low-molecular-weight heparin (depending on body weight, 2,500 or $5,000 \mathrm{U}$ of Low Liquemin $\mathbb{R}$; Roche, Basle, Switzerland). The operations performed in the 125 patients were pneumonectomy (33), bilobectomy

Table 1. - Demographic, spirometric and cardiopulmonary exercise test (CPET) data of the total study population in comparison to patients with and without postoperative complications

\begin{tabular}{|c|c|c|c|c|}
\hline & Total study population & Without complications & With complications & p-value* \\
\hline Patients n $(\%)$ & $125(100)$ & $94(75)$ & $31(25)$ & \\
\hline \multicolumn{5}{|l|}{ Demography } \\
\hline Age yrs & $63 \pm 11(20-80)$ & $63 \pm 11(20-80)$ & $64 \pm 9(43-75)$ & 0.60 \\
\hline Age $>70$ yrs $n(\%)$ & $42(34)$ & $31(33)$ & $11(35)$ & 0.87 \\
\hline Male sex $n(\%)$ & $101(81)$ & $75(80)$ & $26(84)$ & 0.62 \\
\hline $\mathrm{BMI} \mathrm{kg} \cdot \mathrm{m}^{-2}$ & $25 \pm 4(17-37)$ & $25 \pm 4(17-35)$ & $26 \pm 4(19-37)$ & 0.59 \\
\hline Smoking: Current/Ex/Non $n$ & $101 / 24 / 20$ & $84 / 12 / 16$ & $17 / 12 / 4$ & 0.20 \\
\hline Histology: AC/SCC n & $61 / 84$ & $48 / 64$ & $13 / 20$ & 0.41 \\
\hline Stage: I/II/IIIa/IIIb/IV n & $64 / 23 / 23 / 0 / 2$ & $46 / 20 / 16 / 0 / 2$ & $18 / 3 / 7 / 0 / / 0$ & $0.43^{+}$ \\
\hline \multicolumn{5}{|l|}{ Spirometric data } \\
\hline FEV1 L & $2.49 \pm 0.69(0.82-4.41)$ & $2.54 \pm 0.69(0.82-4.41)$ & $2.32 \pm 0.65(0.92-3.55)$ & 0.12 \\
\hline FEV1 \% pred & $87 \pm 19(36-117)$ & $88 \pm 19(45-117)$ & $81 \pm 19(36-114)$ & 0.09 \\
\hline FVC L & $3.63 \pm 0.87(1.29-6.14)$ & $3.68 \pm 0.86(1.57-6.14)$ & $3.47 \pm 0.90(1.29-5.24)$ & 0.26 \\
\hline FVC $\%$ pred & $98 \pm 19(39-145)$ & $100 \pm 19(54-145)$ & $94 \pm 19(39-134)$ & 0.14 \\
\hline \multicolumn{5}{|l|}{ Extent of resection } \\
\hline $\mathrm{SE} / \mathrm{LE} / \mathrm{BLE} / \mathrm{PE}$ n (\%) & $18 / 81 / 10 / 36(12 / 52 / 6 / 23)$ & $16 / 63 / 10 / 23(14 / 56 / 9 / 20)$ & 2/18/0/13 (6/55/0/39) & $0.01^{+}$ \\
\hline \multicolumn{5}{|l|}{ CPET } \\
\hline $\begin{array}{l}\text { Maximal workload (W) } \\
V^{\prime} \mathrm{O}_{2} \text {, max } \mathrm{mL} \cdot \mathrm{min}^{-1}\end{array}$ & $1522 \pm 433(548-2750)$ & $\begin{array}{r}133 \pm 34(60-240) \\
1590 \pm 420(632-2750)\end{array}$ & $\begin{array}{r}122 \pm 30(77-180) \\
1315 \pm 411(548-2185)\end{array}$ & $\begin{array}{l}0.10 \\
0.002\end{array}$ \\
\hline$\%$ pred & $75 \pm 20(33-156)$ & $78 \pm 20(36-156)$ & $66 \pm 20(33-115)$ & 0.004 \\
\hline $\mathrm{mL} \cdot \mathrm{min}^{-1} \cdot \mathrm{kg}$ body weight ${ }^{-1}$ & $21.1 \pm 5.7(9.4-37.8)$ & $22.1 \pm 5.4(13.2-37.8)$ & $17.9 \pm 5.4(9.4-34.0)$ & 0.0003 \\
\hline$\%$ pred body weight $^{-1}$ & $94 \pm 21(46-168)$ & $99 \pm 21(60-168)$ & $80 \pm 17(46-108)$ & $<0.0001$ \\
\hline$V^{\prime}$ E,max $\%$ pred & $88 \pm 25(29-167)$ & $89 \pm 25(29-154)$ & $82 \pm 27(32 \pm 167)$ & 0.18 \\
\hline \multirow[t]{2}{*}{ 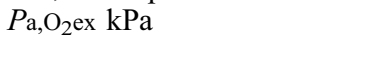 } & $9.5 \pm 1.5(4.1-13.2)$ & $9.5 \pm 1.5(4.1-13.2)$ & $9.1 \pm 1.5(5.3-11.9)$ & 0.22 \\
\hline & $9.5 \pm 1.5(4.1-13.2)$ & $9.5 \pm 1.5(4.1-13.2)$ & $9.1 \pm 1.5(5.3-11.9)$ & 0.22 \\
\hline
\end{tabular}

Data are presented as mean $\pm \mathrm{SD}$ (range) or absolute value. BMI: body mass index; AC: adenocarcinoma; SCC: squamous cell carcinoma; FEV1: forced expiratory volume in one second; FVC: forced vital capacity; SE: segmentectomy; LE: lobectomy; BLE: bilobectomy; PE: pneumonectomy; $V^{\prime} \mathrm{O}_{2}$, max: maximal oxygen uptake; $V^{\prime} \mathrm{E}$,max: maximal exercise minute ventilation; $P \mathrm{a}, \mathrm{O}_{2}$ ex: arterial oxygen tension after exercise; \% pred: percentage of the predicted value. ${ }^{*}$ : significance test, with versus without complications; ${ }^{+}$: Chi-squared test for linear trend. 
(nine), lobectomy (68) and segmentectomy/wedge resection (15).

\section{Postoperative complications}

As generally accepted, complications and deaths were recorded during a 30-day postoperative period. For the sake of comparison, the same definition for postoperative complications as used by SMITH et al. [7], BECHARD and Wetstein [8], Markos et al. [12] and Bolliger et al. [9] was applied (table 2).

\section{Extent of lung tissue resection}

Similar to the formulas for the estimation of postoperative lung function [21], the percentage of lung tissue lost was calculated as the percentage of segments removed, assuming a total number of segments of 19 . For example, a patient undergoing right upper lobectomy, thus, had 3 of 19 segments removed, i.e. $15.8 \%$ of lung tissue. These estimates were used in the multiple logistic regression analysis to "quantify" the intervention.

\section{Data analysis}

Besides methods of descriptive statistics, patients with or without complications were compared by means of the t-test, Mann-Whitney U-test, Chi-squared test or Fisher exact test and Chi-squared test for linear trend as appropriate. For $V^{\prime} \mathrm{O}_{2}$, max $\cdot \mathrm{kg}$ body weight ${ }^{-1}$ (absolute values and $\%$ pred), the sensitivity, specificity and positive predictive values for the identification of patients with postoperative complications were calculated at cut-off values recommended in the literature, i.e. $15 \mathrm{~mL} \cdot \mathrm{min}^{-1} \mathrm{~kg}$ body weight ${ }^{-1}$ [7] and $60 \%$ pred [9], respectively.

Variables with significant differences between patients with and without postoperative complications in the univariate approach were taken as potential predictors of outcome, and, thus, were used in multiple forward stepwise logistic regression analysis to identify independent predictors of postoperative complications. Only a limited number of variables can be entered into this analysis. Thus, the number of variables had to be reduced further based on previous reports and expectancy.

Computations were performed using the SPSS for Win-

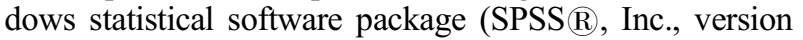
9.0, Statistical Software, Inc., Los Angeles, CA, USA).

Table 2. - Complications within 30 days after lung resection in 125 patients with lung cancer

\begin{tabular}{lc}
\hline Postoperative complications & $\begin{array}{c}\text { Patients } \\
\mathrm{n}(\%)\end{array}$ \\
\hline $\begin{array}{l}\text { Acute carbon dioxide retention }\left(\mathrm{Pa}, \mathrm{CO}_{2}>6 \mathrm{kPa}\right) \\
\text { Prolonged mechanical ventilation }(>48 \mathrm{~h})\end{array}$ & $1(0.8)$ \\
Treated symptomatic cardiac arrhythmia & - \\
Myocardial infarction & $13(10.4)$ \\
Pneumonia (temperature $>38^{\circ} \mathrm{C}$ and purulent & $1(0.8)$ \\
$\quad$ sputum and infiltrate on radiography) & $9(7.2)$ \\
Pulmonary embolism (high probability on & $1(0.8)$ \\
$\quad$ ventilation perfusion scan or angiogram) & \\
Lobar atelectasis (necessitating bronchoscopy) & $4(3.2)$ \\
Death & $2(1.6)$ \\
Total & $31(24.8)$ \\
\hline
\end{tabular}

$P \mathrm{a}, \mathrm{CO}_{2}$ : arterial carbon dioxide tension.
Results are expressed as mean \pm SD with range in parentheses. All tests were two-sided and the significance level was taken at 0.05 .

\section{Results}

A total of 125 patients yielded complete data sets and were included in the study. Two patients were operated on for a single pulmonary metastasis following prior lung cancer surgery. The overall 30 -day postoperative morbidity was $31 / 125$ (25\%; table 2$)$, death occurring in $2 / 125$ $(1.6 \%)$. One patient, a 46-year-old female, with stage IIIa adenocarcinoma died suddenly $1 \mathrm{~h}$ after pneumonectomy due to rupture of the sutured pulmonary artery as confirmed at autopsy. The other patient, a 68 -year-old male with known arterial hypertension underwent lobectomy for stage II squamous cell carcinoma, but died from a haemorrhagic stroke 13 days later.

Neither age, sex, histology, preoperative staging, smoking habits nor spirometric measurements were different in patients with and without complications (table 1). Only exercise data, $V^{\prime} \mathrm{O}_{2}$,max expressed in a variety of ways $\left(\mathrm{mL} \cdot \mathrm{min}^{-1}, \mathrm{~mL} \cdot \mathrm{min}^{-1} \cdot \mathrm{kg}\right.$ body weight ${ }^{-1}$ or $\%$ pred), and the extent of lung tissue resection showed significant differences between the two groups. All Chi-squared tests for linear trend for the exercise parameters were highly significant $\left(V^{\prime} \mathrm{O}_{2}, \max\right.$ (absolute value): $\mathrm{p}=0.0006 ; V^{\prime} \mathrm{O}_{2}$, max (\% pred): $\mathrm{p}=0.003 ; V^{\prime} \mathrm{O}_{2}, \mathrm{max} \cdot \mathrm{kg}$ body weight ${ }^{-1}$ (absolute value): $\mathrm{p}=0.0008 ; V^{\prime} \mathrm{O}_{2}, \max \cdot \mathrm{kg}$ body weight ${ }^{-1}(\%$ pred $)$ : $\mathrm{p}=0.0001$ ) with the most significant $\mathrm{p}$-values obtained for $V^{\prime} \mathrm{O}_{2}$, max $\cdot \mathrm{kg}$ body weight ${ }^{-1}$ (\% pred).

In order to exclude a minimum of patients from operation, a cut-off value with a high specificity for not suffering a complication is important. At the high specificity end, both $V^{\prime} \mathrm{O}_{2}$, max $\cdot \mathrm{kg}$ body weight ${ }^{-1}$ (specificity $94 \%$ and sensitivity $35 \%$ at a cut-off of $15 \mathrm{~mL} \cdot \mathrm{min}^{-1} \cdot \mathrm{kg}$ body weight ${ }^{-1}$ ) and $V^{\prime} \mathrm{O}_{2}$, max $\cdot \mathrm{kg}$ body weight ${ }^{-1}$ (\% pred) (specificity 99\% and sensitivity $16 \%$ at a cut-off of $60 \%$ pred) show excellent performance. However, for maximal specificity, there was a slight advantage to using $V^{\prime} \mathrm{O}_{2}$, max $\cdot \mathrm{kg}$ body weight $^{-1}$ as $\%$ pred compared to absolute values (positive predictive value 86 versus $65 \%$ ). Six of seven (86\%) patients with a $V^{\prime} \mathrm{O}_{2}$, max $\cdot \mathrm{kg}$ body weight ${ }^{-1}$ of $<60 \%$ pred, but only eight of $65(12 \%)$ with values $>90 \%$ pred, exhibited postoperative complications. In comparison, 11 of 17 $(64 \%)$ patients with a $V^{\prime} \mathrm{O}_{2}, \max \cdot \mathrm{kg}$ body weight ${ }^{-1}$ of $<15$ $\mathrm{mL} \cdot \mathrm{min}^{-1}$. body weight ${ }^{-1}$ suffered complications.

Table 3. - Results of stepwise logistic regression analysis

\begin{tabular}{lccccc}
\hline Parameter & Step & Coeff & SEM & $\begin{array}{c}\text { Improvement } \\
\text { Chi-squared }\end{array}$ \\
\hline Constant factor & 0 & 2.9883 & 1.2 & - & - \\
$V^{\prime} \mathrm{O}_{2}$,max $\cdot$ kg body & 1 & -0.0573 & 0.014 & 19.7 & $<0.0001$ \\
$\begin{array}{c}\text { weight }^{-1} \% \text { pred } \\
\text { Resection \% }\end{array}$ & 2 & 0.0343 & 0.015 & 5.3 & 0.02 \\
\hline
\end{tabular}

For the calculation of the probability of postoperative complications (Pcomplication) in a given patient if $\log$ (odds) $=\mu: \mu=2.9883$ $0.0573 V^{\prime} \mathrm{O}_{2}$, max $\cdot \mathrm{kg}$ body weight ${ }^{-1} \%(\%$ pred $)+0.0343$ resection $(\%)$, and Pcomplication $=10^{\mu} /\left(1+10^{\mu}\right)$. See table 4 for probabilities in different situations. Coeff: coefficient; $V^{\prime} \mathrm{O}_{2}$,max: maximal oxygen uptake percentage of the predicted value. 
Table 4. - Probabilities of postoperative complications based on exercise tests and lung resection according to stepwise logistic regression analysis

\begin{tabular}{lcccc}
\hline$V^{\prime} \mathrm{O}_{2}$,max \\
$\%$ pred
\end{tabular}

Probabilities for postoperative complications were calculated independent of the localization assuming 50,31, 20 and 5\% tissue removed for pneumonectomy (PE), bilobectomy (BLE), lobectomy (LE) and segmentectomy/wedge resection (SE/ wedge) respectively. $V^{\prime} \mathrm{O}_{2}$,max: maximal oxygen uptake percentage of the predicted value.

Logistic regression analysis to check the ability of preoperative variables to predict postoperative complications confirmed $V^{\prime} \mathrm{O}_{2}$,max $\cdot \mathrm{kg}$ body weight ${ }^{-1}(\%$ pred $)$ as an independent predictor (table 3). Entering the extent of lung tissue resection into the regression analysis did improve the fit of the model. The calculated probabilities of postoperative complications according to the present model are given in table 4 .

\section{Discussion}

Poor exercise capacity and the estimated extent of lung tissue resection were the best predictors of postoperative complications in the present study population, patients with NSCLC scheduled for lung resection. On univariate analysis, $V^{\prime} \mathrm{O}_{2}$, max $\cdot \mathrm{kg}$ body weight ${ }^{-1}(\%$ pred) was the best independent predictor of postoperative complications. A value of $<60 \%$ pred indicated postoperative complications with an excellent $99 \%$ specificity and a positive predictive value of $86 \%$. The frequently cited absolute cut-off value of $V^{\prime} \mathrm{O}_{2}$, max of $15 \mathrm{~mL} \cdot \mathrm{min}^{-1}$.body weight ${ }^{-1}$ showed had inferior test characteristics in the present study, its positive predictive value being only $65 \%$. Absolute values do not take sex, age or body dimensions into account, and, although easier to use, might exclude certain patients from surgery, such as short elderly females.

Neither age nor spirometric results were predictive of complications in the present study. The multiple regression equation allowed calculation of the probability of postoperative complications by combining exercise performance and estimated extent of lung tissue resection (table 4). Better estimation of the patient's individual postoperative risk based on objective criteria may lead to the introduction of new cost-effective guidelines for the assessment of operability, leading to higher resection rates in such patients. Furthermore, the patient can give informed consent based on an individualized risk assessment.

The present results are in accordance with those of BOLLIGER et al. [9] in a completely different study population and in a non-university environment using easily accessible measures of lung function. In their study, $V^{\prime} \mathrm{O}_{2}$, max $\cdot \mathrm{kg}$ body weight ${ }^{-1}(\%$ pred) proved to be the best single indicator of complications after lung resection. They concluded that patients with a $V^{\prime} \mathrm{O}_{2}, \max \cdot \mathrm{kg}$ body weight $^{-1}$ of $<60 \%$ pred should not undergo pneumonectomy, whereas a $V^{\prime} \mathrm{O}_{2}, \max \cdot \mathrm{kg}$ body weight ${ }^{-1}$ of $>75 \%$ pred was a good indicator of an uneventful postoperative course.

However, in other studies [11-13], exercise performance including $V^{\prime} \mathrm{O}_{2}$, max was not a definite predictor of postoperative complications. Detailed analysis of these reports reveals a variety of definitions of postoperative complications (e.g. including technical complications during the operation), heterogeneous exercise test protocols, retrospective design or low patient numbers.

The estimated extent of lung resection in the present patients also entered the regression model as statistically significant, which is consistent with reports in the literature $[3,22,23]$ and clinical expectancy. Its predictive value is yet to be confirmed by further studies. To choose an anatomical estimation of the amount of lung tissue to be removed has the advantage that no further investigations need to be performed and the present probability model is directly applicable in every lung resection candidate having undergone CPET. Conversely, anatomical estimates are less accurate at predicting postoperative lung function than functional estimates based on radionuclide studies, e.g. ventilation/perfusion scans [24], particularly in patients of borderline operability, as they generally overestimate the functional loss. Using a functional estimate of the amount of remaining lung tissue in further studies might even improve the prediction model.

The overall very low mortality rate and the fact that the two deaths were not predicted by the functional assessments clearly limit the applicability of the present study results on mortality. Mortality rate cut-off values are needed for patients suffering from a disease that invariably leads to death if untreated. Even though there was no definite cut-off value, patients with a $V^{\prime} \mathrm{O}_{2}$, max $\cdot \mathrm{kg}$ body weight $^{-1}$ of $<60 \%$ pred exhibited a very high morbidity. This is in accordance with the study of BOLLIGER et al. [9], in which eight of nine patients with a $V^{\prime} \mathrm{O}_{2}, \mathrm{max} \cdot \mathrm{kg}$ body weight $^{-1}$ of $<60 \%$ pred had complications, including all three patients who died. As the three patients who died had all undergone major resection (two pneumonectomy, one bilobectomy), this cut-off value clearly presents a high risk for major resection. Two other studies [25, 26], which did not account for the extent of resection, independently found $50 \%$ pred to be the lowest acceptable $V^{\prime} \mathrm{O}_{2}$, max for lung resection of high-risk patients. The validity of these suggested lower limits of $V^{\prime} \mathrm{O}_{2}$, max will have to be tested by further prospective studies.

A limitation of the present study is the lack of measurement of the diffusing capacity of the lung for carbon monoxide (DL,CO), which has recently gained in importance [27] and also been integrated into an algorithm for functional evaluation by BOLLIGER and coworkers [24, $28]$. At the time the study was planned, the importance of measuring $D \mathrm{~L}, \mathrm{CO}$ in such patients had not been firmly established and, therefore, this lung function parameter was not used in the present patients.

Previous studies have indicated that mortality in patients of $>70 \mathrm{yrs}$ of age is greater than that in younger patients. In a recent representative survey [3] in 7,899 patients, a mortality rate of $8 \%$ for pneumonectomy and 3\% after lesser resection was found in patients of $>70$ yrs of age, compared to an overall $1.4 \%$ mortality rate in patients of $<60$ yrs of age. Interestingly, age was not an independent 
predictor for postoperative complications in the present regression analysis. The higher frequency of complications in older patients, which was also found in the present study, is probably due to a relatively poorer cardiorespiratory reserve and increased comorbidity as indirectly assessed by CPET and not due to a higher operative risk in older age per se. Nevertheless, in the absence of a real therapeutic alternative, informed older patients may be in favour of an operation even in the light of a higher operative risk given the reasonable life expectancy at $70 \mathrm{yrs}$ of age, $\sim 10.3$ yrs for males and 14.7 yrs for females in Switzerland $[29,30]$. The present $0 \%(0 / 42)$ mortality rate in patients of $>70$ yrs of age, the low mortality rate found in the literature and the fact that the 2-yr survival of such patients is reported to be independent of age [28] encourage an aggressive approach in this population subgroup. Therefore, chronological age alone should not be a reason for excluding patients from sur-gery.

Cardiopulmonary exercise testing is of value for the assessment of operative risk in patients undergoing resection for lung cancer. Maximal oxygen uptake per kilogram of body weight expressed as a percentage of the predicted normal value and the estimated extent of lung tissue resection are probably the best predictors of postoperative complications and should be integrated into the preoperative decision analysis for operability. With the present prediction model an individual's probability of experiencing postoperative complications can be obtained by every physician around the world with largely accessible, cheap and noninvasive measures. Patients with a maximal oxygen uptake per kilogram of body weight of $\leq 60 \%$ of the predicted value have a high risk for postoperative complications and should probably not undergo pneumonectomy. A maximal oxygen uptake per kilogram of body weight of $\geq 90 \%$ of the predicted value is a good marker of a favourable postoperative course. A larger prospective study is needed to clearly establish proper mortality-based cut-off values, the effect on resection rates and the costeffectiveness of cardiopulmonary exercise testing.

\section{References}

1. Beckett WS. Epidemiology and etiology of lung cancer. Clin Chest Med 1993; 14: 1-15.

2. Mountain CF. Revisions in the International System for Staging Lung Cancer. Chest 1997; 111: 1710-1717.

3. Damhuis RAM, Schütte PR. Resection rates and postoperative mortality in 7,899 patients with lung cancer. Eur Respir J 1996; 9: 7-10.

4. Moghissi K, Connolly CK. Resection rates in lung cancer patients. Eur Respir J 1996; 9: 5-6.

5. Pate P, Tenholder MF, Griffin JP, Eastridge CE, Weiman DS. Preoperative assessment of the high-risk patient for lung resection. Ann Thorac Surg 1996; 61: 1494-1500.

6. Eugene J, Brown SE, Light RW, Milne NE, Stemmer EA. Maximum oxygen consumption: a physiologic guide to pulmonary resection. Surg Forum 1982; 33: 260-262.

7. Smith TP, Kinasewitz GT, Tucker WY, Spillers WP, George RB. Exercise capacity as a predictor of postthoracotomy morbidity. Am Rev Respir Dis 1984; 129 : $730-734$.

8. Bechard D, Wetstein L. Assessment of exercise oxygen consumption as preoperative criterion for lung resection. Ann Thorac Surg 1987; 44: 344-349.

9. Bolliger CT, Jordan P, Solèr M, et al. Exercise capacity as a predictor of postoperative complications in lung resec- tion candidates. Am J Respir Crit Care Med 1995; 151: 1472-1480.

10. Bolliger CT, Solèr M, Stulz P, Elusser S, Wyser C, Perruchoud AP. Evaluation of high-risk lung resection candidates: pulmonary haemodynamics versus exercise testing. Respiration 1994; 61: 181-186.

11. Colman NC, Schraufnagel DE, Rivington RN, Pardy RL. Exercise testing in evaluation of patients for lung resection. Am Rev Respir Dis 1982; 125: 604-606.

12. Markos J, Mullan BP, Hillman DR, et al. Preoperative assessment as a predictor of mortality and morbidity after lung resection. Am Rev Respir Dis 1989; 139: 902-910.

13. Holden DA, Rice TW, Stelmach K, et al. Exercise testing, 6-min walk, and stair climb in the evaluation of patients at high risk for pulmonary resection. Chest 1992; 102: 1774-1779.

14. American Thoracic Society. Standardization of spirometry - 1987 update. Am Rev Respir Dis 1987; 136: 1285-1298.

15. American Thoracic Society. Lung function testing: selection of reference values and interpretative strategies. $\mathrm{Am}$ Rev Respir Dis 1991; 144: 1202-1218.

16. Weisman IM, Zeballos JR. Cardiopulmonary exercise testing: the need of standardization. Pulmonary perspectives. Am Rev Chest Physicians 1992; 9: 5-8.

17. Quanjer P. Standardized lung function testing; report of the working party. Bull Eur Physiopathol Respir 1983; 19: 1-95.

18. Jones NL, Campbell JM. Clinical Exercise Testing. 2nd Edn. Philadelphia, W.B. Saunders, 1982.

19. Tschopp JM, Brutsche M, Frey JG, Spiliopoulos A. Cost effectiveness of thoracic surgery for non-small cell lung cancer (NSCLC) without intensive care unit. Am J Respir Crit Care Med 1995; 151: A862.

20. Tschopp JM, Brutsche M, Frey JG, Tatti B, Aymon E, Spiliopoulos A. Chirurgie thoracique pour cancer du poumon non à petites cellules. Coût-bénéfice d'une prise en charge en soins intermédiaires spécialisés. Swiss Surg Suppl 1996; 1: 46-51.

21. Schulz C, Emslander HP, Riedel M. Risikoabschatzung von Patienten vor Lungenresektion. [Risk assessment of patients before lung surgery]. Chirurg 1999; 70: 664-673.

22. Romano PS, Mark DH. Patient and hospital characteristics related to in-hospital mortality after lung cancer resection. Chest 1992; 101: 1332-1337.

23. Whittle J, Steinberg EP, Anderson GF, Herbert R. Use of medicare claims data to evaluate outcomes in elderly patients undergoing lung resections for lung cancer. Chest 1991; 100: 729-734.

24. Bolliger CT, Perruchoud AP. Functional evaluation of the lung resection candidate. Eur Respir J 1998; 11: 198-212.

25. Richter Larsen K, Svendsen UG, Milman N, Brenoe J, Peterson BN. Exercise testing in the preoperative evaluation of patients with bronchogenic carcinoma. Eur Respir $J$ 1997; 10: 1559-1565.

26. Morice RC, Walsh GL, Ali MK, et al. Redefining the lowest exercise peak oxygen consumption acceptable for lung resection of high-risk patients. Chest 1996; 110: 161S.

27. Pierce RJ, Copland JM, Sharpe K, Barter CE. Preoperative risk evaluation for lung cancer resection: predicted postoperative product as a predictor of surgical mortality. Am J Respir Crit Care Med 1994; 150: 947-955.

28. Wyser C, Stulz P, Soler M, et al. Prospective evaluation of an algorithm for the functional assessment of lung resection candidates. Am J Respir Crit Care Med 1999; 159: $1450-1456$.

29. Yearbook. Swiss Federal Statistical Office 1993; p. 313.

30. de Perrot M, Licker M, Reymond MA, Robert J, Spiliopoulos A. Influence of age on operative mortality and long-term survival after lung resection for bronchogenic carcinoma. Eur Respir J 1999; 14: 419-422. 